\title{
Reviews
}

\section{Reconstructing Nature: Alienation, Emancipation and the Division of Labor, by Peter Dickens, London and New York: Routledge, 1996. ix, 224 pp.}

\author{
Reviewed by Eliza Darling, The City University of New York, \\ Graduate School and University Center
}

Peter Dickens' new contribution to environmental sociology, Reconstructing Nature belongs to a category of innovative analysis that transcends the old ideological battles between the proponents of Marx's humanism and those of his historicism, looking instead to reconcile these aspects of Marx's work in his naturalism. Dickens situates his analysis at a particular juncture within this literature--the intersection of epistemology and ontology--by posing the following question: how does the fragmentation of knowledge about nature that characterizes modern capitalist societies mediate our material relationship to nature? The answer, he argues, lies in understanding the alienation of humans from the natural world, the source of which can be found in the ubiquitous productive and social divisions of labor that characterize modernity.

Dickens begins his analysis with the simple but profoundly significant observation that the majority of the denizens of modern capitalist societies have scant knowledge of the productive processes that transform the elements of nature into the commodities we consume. How many people, he asks, can accurately describe the geographical origin of their morning coffee, the process that produced the cup that holds it, the manner of transport of the energy that warms it, or the system of distribution that brings it to their local market? In fact, Dickens argues, the people, technologies and labor processes that produce the goods and services that sustain us are obscure, part of a vaguely conceptualized, nebulous system of global production that somehow gets meat to the butcher and gasoline to the pump. Consumers, he notes, are not the only victims of such alienation. The producers of commodities are equally mystified, isolated for the most part as they are from the totality of the production process even within their own work sites, and all the more so from the production of other commodities or parts of commodities. Our knowledge about the production process constitutes a central aspect of our knowledge about nature, for as Marx notes in the "Economic and Philosophical Manuscripts" (1975), labor is the fundamental mediating force between human beings and the rest of the natural world, making nature our inorganic body and dictating that the transformation of nature results in the transformation of ourselves. Alienation from production, therefore, necessarily entails alienation from nature--for how can we hope to understand the natural world without a clear concept of the capacity for our own activities to transform it?

The transformation of nature by human technologies, Dickens notes, is made possible with the help of science. In the modern capitalist system, humans modify nature with the aid of a scientific establishment that has in large part been co-opted by industry to render nature more profitable. Alienation from nature ensues not merely from the fragmentation of manual labor in the realm of commodity production, but from the fragmentation of 
intellectual labor in the realm of knowledge production. This alienation results in the speciation of the social, natural, and humanistic disciplines and a concomitant obfuscation of the dialectical interrelation of the physical, biological, and social phenomena that comprise the totality of human existence. The alienation of science in an intellectual sense has increased as technologies developed by science have fragmented nature in a physical sense. Bioengineers and other professional mediators of nature increasingly conceptualize organisms as mere genetic segments to be disaggregated and recombined to produce more profitable creatures: fatter cows, hardier tomatoes, and (chillingly) more fertile humans. At a more basic level, Dickens notes, advances in nanotechnology now threaten to develop the ability to reduce organisms to their most basic parts-atoms-and reconstitute them as profitable commodities. The end result of such fragmenting processes is not only the inability to conceive of organisms as total entities in their own right--and with purposes and identities other than the utilitarian ones assigned by science--but the danger of unintended consequences that occur when artificially induced changes in a particular characteristic of a population render it vulnerable to new selective pressures by reducing overall genetic diversity.

In posing this scenario of increasing fragmentation in modern society, Dickens draws upon a long and distinguished tradition of alienation theory in Marxist thought. From Marx himself (1975), who predicted the increasing speciation of human philosophy and natural science, to Lukács (1994), who described the reifying consequences of productive rationalization for workers, to Braverman (1974), who noted the progressive deskilling of the American working class under Taylorism, to Harvey (1989), who pioneered the theory of fragmentation in the era of postmodern flexibility, the division of labor that has characterized capitalist production from the time of Adam Smith's pin factory has been condemned for its debilitating effects on both mind and body, blamed for the disaffection of both intellectual and manual laborers, and attributed the cause of our conceptual inability to recognize the connections between a host of reified dichotomies. Similarly, following Marxist scholars from Engels to the Frankfurt School, Dickens seeks the resolution of such alienated thought patterns in dialectics, as both an epistemological and an ontological remedy to the ills of Cartesian dualism. Following the critical realist epistemology of Roy Bhaskar (1978, 1994), Dickens argues that a truly dialectical conceptualization of the human/nature relationship draws upon Marx's notion of the "humanization of nature" and the "naturalization of humans" by recognizing the emergent relationship between physical, biological, and social phenomena. Biological processes, in other words, are based upon physical properties, but are irreducible to them, just as social processes are rooted in biological processes, but irreducible to them. A critical realist perspective thus moves between levels of abstraction and concretion, examining underlying causal mechanisms as well as overdetermining, localized contingencies. A realist dialectics of nature, then, cannot exclude any single sphere of knowledge, and necessarily transcends the spurious disciplinary dichotomies that characterize modern academe.

Dickens takes a step beyond traditional dialectical investigations, however, by examining not only the fragmentation of knowledge within the institution of science, broadly conceived, but the alienation of abstract, scientific knowledge about nature from the experiential "lay" knowledge of ordinary people. Dickens argues that lay conceptions of nature (and of science itself) have been underemphasized in analyses of human/nature relationships. The accumulated knowledge of farmers, pastoralists, fishermen--people who by virtue of their daily productive activities enjoy an intimate relationship with nature and 
an extensive knowledge of its mechanisms--is systematically delegitimated by science with help from the state, which relies upon communities of technical professionals for advice on environmental policy which it then imposes upon local producers. The result, Dickens argues, is a valorization of abstract scientific knowledge to the exclusion of localized lay knowledge about environmental processes--an alienation that is further exacerbated by increasing scientific intervention in the production of food and the management of resources. Dickens attempts to remedy the dearth of information on lay conceptualizations of nature by incorporating data from Sussex University's MassObservation Archive project, which in 1992 gathered information via an open-ended, written questionnaire asking the British public to describe its opinions about issues of environmental degradation and economic development. Dickens concludes that the responses demonstrate an alienation of ordinary people from knowledge about the environment, exhibited by their general confusion about causal relationships in the natural world and mixed opinions about the efficacy of science as a way of understanding nature. Lay conceptions of the natural world, Dickens argues, lack the structured theoretical framework employed by scientists, and instead rely upon the familiar metaphors of social relationships to interpret natural events.

Although it is the shortest chapter in the book, this section devoted to the MassObservation Archive Directive is of central importance because it constitutes the book's only systematic attempt at primary research. It is also the place where the weaknesses in Dickens' argument begin to manifest, and it is here that a critique of the book must begin. Dickens' description of the Mass-Observation Archive survey demonstrates the methodological difficulties faced by social scientists who venture into the conceptually murky arena of belief systems. Remote questionnaires, despite attempts to make them open-ended and interactive, remain a limited technique for assessing informants' complex interpretations of the natural world and their relationship to it. As part of a broader methodological approach, questionnaires of this type can contribute limited information on human conceptions of the environment. In this case, Dickens' account would have benefited enormously from the addition of ethnographic research based on extensive, open-ended, conversational interviews that allowed informants to take issue with the Archive's framing of the questions themselves, inviting respondents to redefine and restate the issues according to their own conceptual worldviews, and providing an opportunity for the researcher to pose follow-up questions that would allow for considerable elaboration. Furthermore, participant-observation of the classical anthropological kind allows researchers to begin to distinguish between what people say and what they do, a distinction that can offer insight into conflicting and contradictory, yet concurrent, attitudes toward the environment. In short, the implementation of a more thorough methodological approach to data collection would have added a measure of texture and depth to Dickens' project that his anthropological readers, as well as many of his fellow sociologists, will miss. Though limited in quantitative range, ethnography is infinitely superior to the survey in depth, and though time-consuming and cumbersome, it remains the single most thorough interpretive tool at a researcher's disposal.

Dickens' incorporation of data from the Mass-Observation Archive may trouble readers not only for the limitations of its methodological approach, but for the conclusions he draws from the responses as well. Several of the respondents offer surprisingly complex and insightful observations about environmental degradation and its relationship to science. One informant went so far as to draw a diagram illustrating possible connections between human poverty, climate change, and habitat destruction to support 
her assertion that problems of development and environment are interrelated. Another informant offered a personalized version of Dickens' own thesis--that modern and (significantly) middle class British people are so isolated from production that they do not have an accurate understanding of the relationship between their own consumption habits and environmental degradation, as well as (significantly) the immiseration of other human populations. Yet another informant noted a factor that Dickens himself addresses in only a cursory fashion: that science itself, far from being a homogeneous producer of a set of uniform, abstract conclusions about the environment, cannot even muster a united front on issues like ozone depletion or global warming, leaving her to conclude, "What are ordinary mortals to believe or do if we don't know what the truth is?" (p. 97). Far from displaying ignorance or confusion about environmental problems, the respondents quoted by Dickens appear to have at least as good a grasp of the fundamental questions as most ecologists. And though they may display a certain amount of uncertainty about the existence, extent, or cause of environmental degradation, they also display an awareness of their own uncertainty, as well as a cognizance of the uncertainty of science itself. And this fact alone deserves much more attention--and encourages much more hope--than Dickens is willing to concede.

Dickens concludes from his analysis of the data on lay knowledge that "metaphors and analogies borrowed from familiar social experiences are being projected onto processes and relationships which remain beyond comprehension. 'Environmental misperceptions' are the result" (p. 101). The irony of this statement is that science itself has been challenged on these very grounds. Recent research by Emily Martin (1993, 1994) and Donna Haraway $(1989,1991)$, among others, has pointed to the problematic tendency of biomedical researchers to describe natural processes with culture-bound, patriarchal analogies that not only belie the supposed "objectivity" of scientists, but color the very questions scientists use to frame their inquiries about the natural world. Which brings us to the most significant difficulty of Dickens' analysis: the distinction between scientific and lay knowledge about the environment is a spurious one. In light of the very division of intellectual labor Dickens describes, all scientists are "laymen" in some areas of knowledge. Anthropologists, for instance, rarely claim expertise in the realm of physics, and whereas the scientistic hierarchy of the academic disciplines may allow physicists to lay some claim to knowledge about culture, it is doubtful that most would proclaim themselves experts. Nor do scientists of the same ilk succeed uniformly in (or even agree upon) the employment of abstract theoretical frameworks to understand nature. Furthermore, even within disciplinary boundaries, science can hardly be described as an egalitarian institution. The increasing division of labor in academia has created a population of intellectual laborers divided along lines of class, characterized by differential access to and control over the means of knowledge production, as well as an uneven level of consciousness with regard to the exploitative labor practices that allow universities to cut costs by relying on part-time, low-wage, no-benefit adjunct labor. And these divisions do not even begin to account for differences in industrial science, produced in nonacademic settings and subject to the stratifying forces of its own unique political economy. In the last analysis, science itself, embedded in modern capitalist relations of production, is rife with enough contradictions, uncertainties and even hostilities to call into question its capacity to stand as a homogeneous unit.

We might pose similar questions about the category of "lay" knowledge, particularly given the hierarchical power structures within and between societies that dictate very different material relationships between people and between people and nature. Although 
Dickens is well aware of these hierarchical structures, as well as those that characterize science, he never manages to address power in a systematic way as a mediator of knowledge about nature. Unfortunately, he allows the distinction between "lay" and "scientific" knowledge to remain in this unproblematized, reified state, and his readers are left to wonder why he didn't take the cue from his informants and question his own facile categorization.

While Dickens' book contains some serious conceptual and methodological problems, it nonetheless succeeds in drawing upon the most significant concepts of Marx's ontology -alienation, dialectics, and the division of labor-to set a research agenda for scholars of political ecology. Dickens challenges us to conduct the necessary ethnographic research on perceptions of science and nature, illuminates the need for interdisciplinary collaboration between the natural and social sciences, and effectively demonstrates the continued relevance of Marxist theory for political ecological research. Indeed, it is a testament to the veracity of dialectical ontology that whereas many areas of Marxist theory lie dormant today - victims of the disenchantment with state socialism, the rise to dominance of neoconservative governments in the United States and Britain, and the fragmentation of labor politics in the face of the increasing flexibility of capital - inquiry at the intersection of the red and the green flourishes. Dickens, like others who have pioneered green Marxist theory, is to be commended for his courage in standing against the tide of idealist constructionism to consider the dialectical relationship between the historical, material world and our ideas about it.

\section{References Cited}

Bhaskar, Roy.

1978. A Realist Theory of Science. Second Edition. Brighton: Harvester.

Bhaskar, Roy.

1994. Dialectic: The Pulse of Freedom. London: Verso.

Braverman, Harry.

1974. Labor and Monopoly Capital: The Degradation of Work in the Twentieth Century. New York: Monthly Press.

Haraway, Donna

1989. Primate Visions: Gender, Race and Nature in the World of Modern Science.

New York: Routledge.

Haraway, Donna.

1991. Simians, Cyborgs and Women: The Reinvention of Nature. London: Free Association.

Harvey, David

1989. The Condition of Postmodernity. Oxford: Blackwell.

Lukács, Georg

1994. History and Class Consciousness: Studies in Marxist Dialects. Rodney

Livingstone, trans. Cambridge, MA: The MIT Press.

Martin, Emily

1993. The Woman in the Body: A Cultural Analysis of Reproduction. Milton Keynes: Open University Press.

Martin, Emily.

1994. Flexible Bodies: Tracking Immunity in American Culture from the Days of Polio to the Age of AIDS. Boston: Beacon Press. 
Marx, Karl

1975. Early Writings. Quinton Hoare, ed. Rodney Livingstone and Gregor Benton, trans. New York: Penguin Books.

\section{Uncommon Ground: Cultural Landscapes and Environmental Values (1997), by Veronica Strang, Oxford ; New York : Berg, 1997. xiv, 309 pp.}

\section{Reviewed by Shelley Greer, School of Anthropology \& Archaeology, James Cook University, Townsville, Queensland Australia.}

In this work, Strang examines concepts of "landscape" and "environment", comparing the perspectives of Aboriginal people and pastoralists living in the Mitchell River catchment of Cape York Peninsula. She does this by referring to the history of this part of Cape York, the "landscapes of the past"; by describing the contemporary cultural landscapes of both groups and the way in which they describe and organize space, and by undertaking a comparison of the values invested in land through education, representations and cosmology.

The concept of comparing the values of these two groups is extremely interesting and timely, given the current debate in Australia surrounding Native Title. Strang's study is all the more relevant as the geographic area she has chosen for her study borders the traditional lands of the Wik people whose Native Title claim has served, after Mabo, as the test case for Native Title through both the legal and political systems.

Strang makes several important points. First, she convincingly makes the point that concepts such as "landscape" and "environment" are culturally constructed and that this obviously affects the "value" of these. In this regard, Strang's findings resonate with other work in Cape York that critiques the notion of 'heritage' in terms of indigenous perspectives of landscape (S. Greer 1995). Perspectives such as these are particularly important in areas like Cape York which are often constructed as "untouched environments" and therefore subject to a range of legislative requirements. Strang's work challenges contemporary management practice which tends to view the environment as an objective (scientific) reality which has "natural" and "cultural" values. As Strang points out, "value" is embedded within the cultural construction. Furthermore, there is a perception that "natural resources" (at least) can be objectively quantified and on this basis, given value. This quantification of the environment is based on scientific values that are, of course, drawn from a particular cultural construction. In addition, there has been a tendency to conflate Aboriginal values with those of environmentalists without recognition that although there may well be some common ground, they are usually drawn from different cultural constructions.

In her description and analysis of the pastoralist group in the Mitchell River catchment, Strang makes the distinction between those who have had long-term associations with the region and those that are employees of absentee landowners. The latter are characterized as highly mobile, staying in the region for relatively short periods and having a tendency to be focused on the primary economic activity, i.e. grazing cattle: 